\title{
Long-Lasting Response to Trabectedin in a Patient with Metastatic Uterine Leiomyosarcoma: A Case Report
}

\author{
Viktoria-Anna Nteli ${ }^{a} \quad$ Wolfgang Knauf ${ }^{b}$ Anja Janton-Klein ${ }^{a}$ \\ Samer El-Safadi ${ }^{\mathrm{a}}$ \\ ${ }^{a}$ Department of Gynecology and Obstetrics, St. Elisabethenkrankenhaus, \\ Frankfurt am Main, Germany; ${ }^{b}$ Department of Haematology and Oncology, \\ Agaplesion Bethanien Krankenhaus, Frankfurt am Main, Germany
}

\section{Keywords}

Trabectedin · Uterine leiomyosarcoma · Metastasis · Recurrence

\begin{abstract}
Background: Uterine leiomyosarcoma (uLMS) is a rare tumor that accounts for $1 \%$ of all uterine malignancies. In spite of adequate surgical resection of uLMS, even in the early stage, patients remain at high risk for local and distant recurrence. Therefore, the treatment of advanced ULMS represents a considerable challenge. Methods: We report the case of a 47year-old woman who presented with uLMS with abnormal vaginal bleeding. Results: The patient underwent a total hysterectomy and bilateral adnexectomy, which was followed by 1 year progression-free survival without adjuvant therapy. Thereafter, new lung metastases and local progression at the vaginal stump were observed. Chemotherapy with ifosfamide and doxorubicin was administered. However, after 4 cycles, a CT scan revealed disease progression in the lung metastases. Subsequently, the patient was treated with trabectedin at a dose of $1.5 \mathrm{mg} / \mathrm{m}^{2}$ for 6 cycles resulting in complete remission of the lung metastases as well as partial remission of the mass in the vaginal stump after 9 cycles of trabectedin. The patient is
\end{abstract}




\section{Case Reports in Oncology}

Nteli et al.: Long-Lasting Response to Trabectedin in a Patient with Metastatic Uterine Leiomyosarcoma: A Case Report

currently on maintenance therapy with trabectedin and has no recurrence. Conclusion: Trabectedin seems to be an efficient option for patients with uLMS as demonstrated by a long-lasting response in a pretreated patient with an acceptable safety profile with no signs of cumulative toxicity.

(C) 2018 The Author(s)

Published by S. Karger AG, Basel

\section{Introduction}

Leiomyosarcomas are the fourth most frequent histological subtype of sarcomas, with an incidence of $11 \%$ [1]. Uterine leiomyosarcoma (uLMS) is a rare tumor that accounts for $1 \%$ of all uterine malignancies and is often diagnosed incidentally following hysterectomy [2]. It is reported that the overall age-adjusted incidence for black women is twice higher than that of Caucasians and women of other ethnic origin [3]. Although several features on ultrasonography and magnetic resonance imaging (MRI) can raise suspicion of a uterine sarcoma, there are no pathognomonic features on any imaging technique [4]. The most common histological types of uterine sarcoma are leiomyosarcoma (63\%), endometrial stromal sarcoma (21\%), adenosarcoma (6\%), undifferentiated sarcoma (5\%), and other types (5\%). Instead, carcinosarcoma is a mixed tumor, which nowadays is regarded as a subset of endometrial carcinoma.

Prognosis of uterine sarcomas is poor, with a 5-year survival rate as low as $30 \%$. Total abdominal hysterectomy with or without bilateral salpingo-oophorectomy is the cornerstone treatment of localized uLMS and the only potentially curative treatment. Noteworthy, tumor-free resection margins at primary surgery and disease stage are the most important prognostic factors for survival for all types of uterine sarcoma [5, 6]. In addition, there is no good evidence for the routine use of adjuvant chemotherapy or pelvic radiotherapy since no data have conclusively proven that those therapies are of any benefit for patients with localized resectable disease $[7,8]$. The ovary can be preserved in premenopausal women with early-stage uLMS, and routine lymphadenectomy is not necessary unless enlarged lymph nodes are present [9]. On the other hand, standard first-line chemotherapy for disseminated or unresectable disease generally involves palliative systemic chemotherapy regimens with poor prognosis with a median overall survival (OS) of $\sim 12$ months [10]. The most active first-line chemotherapy for advanced or recurrent disease has not changed for the last $\sim 30$ years and remains doxorubicin with or without ifosfamide [11] and other nonapproved active but more toxic treatments such as gemcitabine alone or in combination with docetaxel [12-14]. A variety of newer cytotoxic agents, including trabectedin, pazopanib, and olaratumab, have already been approved by the US Food and Drug Administration (FDA), whilst others such as targeted therapies, aromatase inhibitors, and immunotherapies have demonstrated very modest activity in uLMS and are still under active investigation.

Trabectedin (Yondelis ${ }^{\circledR}$ ) is a natural substance isolated from the Caribbean marine invertebrate Ecteinascidia turbinata and currently produced synthetically. It has pleiotropic mechanisms of action, including the interaction with the minor groove of the DNA double helix, affecting transcription of different genes involved in DNA repair and, thus, facilitating lethal DNA strand breaks $[15,16]$. In addition to inducing direct growth inhibition and death of malignant cells, it also has selective anti-inflammatory and immunomodulatory properties 


\section{Case Reports in Oncology}

Case Rep Oncol 2018;11:81-89

DOI: $10.1159 / 000486638$

(C) 2018 The Author(s). Published by S. Karger AG, Basel www.karger.com/cro

Nteli et al.: Long-Lasting Response to Trabectedin in a Patient with Metastatic Uterine Leiomyosarcoma: A Case Report

because of the inhibition of factors that promote tumor growth, angiogenesis, and metastasis [17]. Trabectedin was first approved in the European Union and in over 70 countries across the world for the treatment of patients with advanced soft tissue sarcoma after failure of anthracyclines and ifosfamide or for patients who are unsuited to receive these agents. In 2015 , following the analysis of a pivotal phase III study that evaluated the efficacy and safety of trabectedin compared with dacarbazine in patients with advanced liposarcoma or leiomyosarcoma after failure of previous anthracycline-containing chemotherapy, trabectedin was also approved by the US FDA $[18,19]$. Recently, the results of an analysis in women with uLMS who had received prior anthracycline therapy and were treated in a large phase III trial reported that trabectedin treatment results in significantly longer progression-free survival (PFS) as compared with dacarbazine and has an acceptable safety profile [20].

Here we present a case of a metastatic uLMS with a complete remission of lung metastases after 6 cycles of trabectedin as well as a partial remission of the mass in the vaginal stump after 3 additional cycles of trabectedin.

\section{Case Presentation}

We report the case of a 47-year-old biparous woman who was initially referred to our clinic in April 2015 with over 1 month of abnormal vaginal bleeding. The transvaginal ultrasonography showed an enlarged uterus with an $8 \times 8 \mathrm{~cm}$ uterine solid mass, partially vasculated. The abdominal and pelvic computed tomography (CT) scan revealed an $11.9 \times 9.6 \times 12$ $\mathrm{cm}$ enlarged uterus with inhomogeneous contrast enhancement and many irregular nodes, such as a mass with small calcifications caudal from the cervix. A hysteroscopy with a fractional curettage was conducted with normal histological findings. Thereafter, the patient underwent laparotomy with hysterectomy and bilateral salpingectomy. The pathology report described a moderately differentiated uterine leiomyosarcoma (G2) according to TNM classification (p T1b [10 cm], L0, Nx, V0, R0, G2). The tumor had the following features: 26 mitotic figures per 10 high-power fields, tumor cell necrosis, and atypical cells. No adjuvant therapy was indicated. CT scan of the chest, abdomen, and pelvis were repeated every 3 months. After being free of progression for approximately 1 year, 2 tiny lesions of about $3 \mathrm{~mm}$ appeared on the left inferior lung lobe. Because of an uncertain diagnosis, a control CT scan was carried out after 2 months. In June 2016, a CT scan showed 3 lesions, about $4 \mathrm{~mm}$ each, on the left inferior lung lobe, 5 new small lesions on the right lung, as well as recurrence of the tumor on the vaginal stump of about $3 \times 4 \mathrm{~cm}$ (Fig. 1). The patient underwent a total of 4 cycles of the palliative chemotherapy with the combination of doxorubicin and ifosfamide. In the meantime, the patient was admitted twice to our hospital with grade 3 hematologic toxicity. In October 2016, a CT scan showed a progression in the already existing lung lesions as well as new lung lesions (Fig. 2). Subsequently, the patient was treated with second-line chemotherapy with trabectedin at the recommended dose of $1.5 \mathrm{mg} / \mathrm{m}^{2}$ given as a 24-h infusion every 3 weeks ( $\mathrm{q} 3 \mathrm{w}$ ). The first evaluation performed after 3 cycles showed a partial remission of the lung lesions and the vaginal stump according to the Response Evaluation Criteria in Solid Tumors (RECIST v.1.1) [21]. In April 2017, a complete remission of the lung lesions was documented after cycle 6 (Fig. 3). After 9 cycles of trabectedin, a CT scan showed the further complete remission of the lung lesions (Fig. 3) and a 


\section{Case Reports in Oncology}

Case Rep Oncol 2018;11:81-89

DOI: $10.1159 / 000486638$

(C) 2018 The Author(s). Published by S. Karger AG, Basel www.karger.com/cro

Nteli et al.: Long-Lasting Response to Trabectedin in a Patient with Metastatic Uterine Leiomyosarcoma: A Case Report

further partial remission of the vaginal stump (Fig. 4) with light decrease in growth of the right $(3.1 \times 1.2 \mathrm{~cm})$ and left $(1.8 \times 1.1 \mathrm{~cm})$ vaginal stumps. During the treatment, trabectedin did not induce any side effect in our patient who had a very good quality of life during the whole treatment. Currently, the patient remains asymptomatic and is on maintenance therapy with trabectedin with no recurrences.

\section{Discussion}

This case highlights the role of trabectedin as a chemotherapeutic agent which significantly contributes to the therapeutic strategy of uLMS after failure of standard treatment options for care. In this case, after 6 cycles of trabectedin treatment, a durable response was registered in this pretreated patient with metastatic uLMS. Additionally, the use of trabectedin resulted in long-lasting response, which did not occur at the expense of treatmentrelated toxicities and worsening in patient quality of life.

The results from the prospective phase II studies of trabectedin in patients with measurable advanced, persistent, or recurrent uLMS reported that trabectedin is a promising regimen for those patients. The Gynecologic Oncology Group treated 20 patients with chemotherapy-naive advanced, persistent, or recurrent uLMS and documented disease progression with trabectedin $1.5 \mathrm{mg} / \mathrm{m}^{2}$ as a 24-h infusion q3w [22]. Of those, 2 patients achieved partial responses $(10 \%)$, and stable disease (SD) was reported in 10 patients $(50 \%)$ for a disease control rate (DCR) of $60 \%$. In that study, the median PFS and OS were 5.8 and $26.1+$ months, respectively. A French Sarcoma Group phase II study of the combination of doxorubicin $60 \mathrm{mg} / \mathrm{m}^{2}$ with trabectedin $1.1 \mathrm{mg} / \mathrm{m}^{2}$ as the first-line treatment of advanced uLMS showed that 28 out of 47 evaluable patients achieved a partial response (59.6\%) [23]. That study also showed that a further 13 patients (27.7\%) had SD giving a DCR of $87.2 \%$. The median PFS was 8.2 months and the median OS was 20.2 months. These efficacy results compare favorably with the outcomes reported in other studies with combination regimens in the first-line treatment of uLMS, whereas the safety results of the combination were better than that of the doxorubicin plus ifosfamide and gemcitabine plus docetaxel combinations given in the first-line setting. A pooled analysis of data from 62 heavily pretreated patients with uLMS and treated with trabectedin monotherapy in 5 phase II trials was also performed. Across trials, partial responses were observed in 11 patients (17.7\%) and SD in 20 patients $(32.3 \%)$ for a DCR of $50.0 \%$. For the entire patient population, the median PFS was 2.5 months and the median OS was 12.1 months [24]. The most common grade $3 / 4$ adverse events were neutropenia (41.9\%) and transient increases of ALT and AST observed in 43.5 and $30.6 \%$ of patients, respectively. Indeed, the current treatment options for patients with uLMS are frequently guided by safety considerations and convenience. Therefore, it is important to notice that these results indicate that trabectedin is an active single agent for the treatment of advanced uLMS with a safety profile that favorably compares with those of other active drugs $[11,12]$.

In addition, a retrospective analysis of 66 patients with uLMS who had failed a median of 3 prior cytotoxic lines and were treated with trabectedin was also carried out [25]. Eleven patients (16\%) achieved a partial response and 23 (35\%) had SD for a DCR of 51.0\%. The median PFS of the entire cohort was 3.3 months and the median OS was 14.4 months. Ac- 
cordingly, the efficacy outcomes of this analysis in an unselected patient population and representative of routine clinical practice were consistent with those seen in more selective populations enrolled in clinical trials. Finally, the peculiar activity of trabectedin in metastatic uLMS has also been suggested in some case reports (Table 1).

In the absence of large randomized studies, institutional case series can provide useful insights into the real-world efficacy, toxicity, and management of patients receiving trabectedin. Trabectedin's low toxicity profile, good tolerability, and observed activity commonly permit to continue with the treatment for prolonged periods of time. Further clinical research is warranted to examine the long-term results of trabectedin in other active combination regimens in ULMS. An Italian randomized phase II TAUL trial (NCT02249702) is currently testing the activity of trabectedin and gemcitabine plus docetaxel in metastatic or locally relapsed uLMS pretreated with conventional chemotherapy.

\section{Acknowledgements}

The authors thank PharmaMar for review and editorial assistance.

\section{Statement of Ethics}

The authors have no ethical conflicts to declare.

\section{Disclosure Statement}

The authors declare that there are no conflicts of interest regarding the publication of this paper.

\section{References}

1 Ducimetière F, Lurkin A, Ranchère-Vince $D$, Decouvelaere AV, Péoc'h $M$, Istier L et al. Incidence of sarcoma histotypes and molecular subtypes in a prospective epidemiological study with central pathology review and molecular testing. PLoS One. 2011;6(8):e20294.

2 Ricci S, Stone RL, Fader AN. Uterine leiomyosarcoma: Epidemiology, contemporary treatment strategies and the impact of uterine morcellation. Gynecol Oncol. 2017 Apr;145(1):208-16.

3 Brooks SE, Zhan M, Cote T, Baquet CR. Surveillance, epidemiology, and end results analysis of 2677 cases of uterine sarcoma 1989-1999. Gynecol Oncol. 2004 Apr;93(1):204-8.

4 Amant F, Coosemans A, Debiec-Rychter M, Timmerman D, Vergote I. Clinical management of uterine sarcomas. Lancet Oncol. 2009 Dec;10(12):1188-98.

5 Tropé CG, Abeler VM, Kristensen GB. Diagnosis and treatment of sarcoma of the uterus. A review. Acta Oncol. 2012 Jul;51(6):694-705.

6 Park JY, Kim DY, Suh DS, Kim JH, Kim YM, Kim YT et al. Prognostic factors and treatment outcomes of patients with uterine sarcoma: analysis of 127 patients at a single institution, 1989-2007. J Cancer Res Clin Oncol. 2008 Dec;134(12):1277-87.

7 Kapp DS, Shin JY, Chan JK. Prognostic factors and survival in 1396 patients with uterine leiomyosarcomas: emphasis on impact of lymphadenectomy and oophorectomy. Cancer. 2008 Feb;112(4):820-30. 
Nteli et al.: Long-Lasting Response to Trabectedin in a Patient with Metastatic Uterine Leiomyosarcoma: A Case Report

8 Woll PJ, Reichardt P, Le Cesne A, Bonvalot S, Azzarelli A, Hoekstra HJ et al.; EORTC Soft Tissue and Bone Sarcoma Group and the NCIC Clinical Trials Group Sarcoma Disease Site Committee. Adjuvant chemotherapy with doxorubicin, ifosfamide, and lenograstim for resected soft-tissue sarcoma (EORTC 62931): a multicentre randomised controlled trial. Lancet Oncol. 2012 Oct;13(10):1045-54.

9 Amant F, Lorusso D, Mustea A, Duffaud F, Pautier P. Management Strategies in Advanced Uterine Leiomyosarcoma: Focus on Trabectedin. Sarcoma. 2015;2015:704124.

10 Zivanovic O, Leitao MM, Iasonos A, Jacks LM, Zhou Q, Abu-Rustum NR et al. Stage-specific outcomes of patients with uterine leiomyosarcoma: a comparison of the international Federation of gynecology and obstetrics and american joint committee on cancer staging systems. J Clin Oncol. 2009 Apr;27(12):2066-72.

11 Judson I, Verweij J, Gelderblom H, Hartmann JT, Schöffski P, Blay JY et al; European Organisation and Treatment of Cancer Soft Tissue and Bone Sarcoma Group. Doxorubicin alone versus intensified doxorubicin plus ifosfamide for first-line treatment of advanced or metastatic soft-tissue sarcoma: a randomised controlled phase 3 trial. Lancet Oncol. 2014 Apr;15(4):415-23.

12 Hensley ML. Update on gemcitabine and docetaxel combination therapy for primary and metastatic sarcomas. Curr Opin Oncol. 2010 Jul;22(4):356-61.

13 Tap WD. GeDDiS: insight into frontline therapy in soft tissue sarcoma. Lancet Oncol. 2017 Oct;18(10): 1297-9.

14 Seddon B, Strauss SJ, Whelan J, Leahy M, Woll PJ, Cowie F et al. Gemcitabine and docetaxel versus doxorubicin as first-line treatment in previously untreated advanced unresectable or metastatic soft-tissue sarcomas (GeDDiS): a randomised controlled phase 3 trial. Lancet Oncol. 2017 Oct;18(10):1397-410.

15 D'Incalci M. Trabectedin mechanism of action: what's new? Future Oncol. 2013 Dec;9(12 Suppl):5-10.

16 D'Incalci M, Galmarini CM. A review of trabectedin (ET-743): a unique mechanism of action. Mol Cancer Ther. 2010 Aug;9(8):2157-63.

17 Larsen AK, Galmarini CM, D’Incalci M. Unique features of trabectedin mechanism of action. Cancer Chemother Pharmacol. 2016 Apr;77(4):663-71.

18 Demetri GD, von Mehren M, Jones RL, Hensley ML, Schuetze SM, Staddon A et al. Efficacy and safety of trabectedin or dacarbazine for metastatic liposarcoma or leiomyosarcoma after failure of conventional chemotherapy: results of a phase III randomized multicenter clinical trial. J Clin Oncol. 2016 Mar;34(8): 786-93.

19 Gordon EM, Sankhala KK, Chawla N, Chawla SP. Trabectedin for Soft Tissue Sarcoma: Current Status and Future Perspectives. Adv Ther. 2016 Jul;33(7):1055-71.

20 Hensley ML, Patel SR, von Mehren M, Ganjoo K, Jones RL, Staddon A et al. Efficacy and safety of trabectedin or dacarbazine in patients with advanced uterine leiomyosarcoma after failure of anthracycline-based chemotherapy: subgroup analysis of a phase 3, randomized clinical trial. Gynecol Oncol. 2017 Sep; 146(3):531-7.

21 Eisenhauer EA, Therasse P, Bogaerts J, Schwartz LH, Sargent D, Ford R et al. New response evaluation criteria in solid tumours: revised RECIST guideline (version 1.1). Eur J Cancer. 2009 Jan;45(2):228-47.

22 Monk BJ, Blessing JA, Street DG, Muller CY, Burke JJ, Hensley ML. A phase II evaluation of trabectedin in the treatment of advanced, persistent, or recurrent uterine leiomyosarcoma: a gynecologic oncology group study. Gynecol Oncol. 2012 Jan;124(1):48-52.

23 Pautier P, Floquet A, Chevreau C, Penel N, Guillemet C, Delcambre C et al.; French Sarcoma Group. Trabectedin in combination with doxorubicin for first-line treatment of advanced uterine or soft-tissue leiomyosarcoma (LMS-02): a non-randomised, multicentre, phase 2 trial. Lancet Oncol. 2015 Apr;16(4): 457-64.

24 Judson IR, Blay J, Chawla SP, Radford JA, Le Cesne A, Verweij J et al. Trabectedin (Tr) in the treatment of advanced uterine leiomyosarcomas (U-LMS): Results of a pooled analysis of five single-agent phase II studies using the recommended dose. J Clin Oncol. 2010 May;28(15 Suppl):10028.

25 Sanfilippo R, Grosso F, Jones RL, Banerjee S, Pilotti S, D’Incalci M et al. Trabectedin in advanced uterine leiomyosarcomas: a retrospective case series analysis from two reference centers. Gynecol Oncol. 2011 Dec;123(3):553-6.

26 Tavella K, Villanucci A, Vannini L, Lavacchi D, Montelatici S, Amunni G et al. Stable disease in a patient with metastatic leiomyosarcoma treated with trabectedin. Anticancer Drugs. 2017 Apr;28(4):465-8.

27 Bongiovanni A, Riva N, Ricci M, Mercatali L, Liverani C, La Manna F et al. Long-lasting activity of trabectedin in refractory uterine leiomyosarcoma: a case report. BMC Cancer. 2015 Dec;15(1):998.

28 Corrado G, Salutari V, Fuoco G, Lucidi A, Ferrandina G. Prolonged clinical response to trabectedin in a heavily pretreated patient with advanced uterine leiomyosarcoma: a case report and literature review. Gynecol Oncol. 2011 May;121(2):416-7. 


\section{Case Reports in Oncology}

Case Rep Oncol 2018;11:81-89
\begin{tabular}{l|l}
\hline DOI: $10.1159 / 000486638$ & $\begin{array}{l}\text { (c) } 2018 \text { The Author(s). Published by S. Karger AG, Basel } \\
\text { www.karger.com/cro }\end{array}$
\end{tabular}

Nteli et al.: Long-Lasting Response to Trabectedin in a Patient with Metastatic Uterine Leiomyosarcoma: A Case Report

29 Amant F, Coosemans A, Renard V, Everaert E, Vergote I. Clinical outcome of ET-743 (Trabectedin; Yondelis) in high-grade uterine sarcomas: report on five patients and a review of the literature. Int J Gynecol Cancer. 2009 Feb;19(2):245-8.

30 Tewari D, Saffari B, Cowan C, Wallick AC, Koontz MZ, Monk BJ. Activity of trabectedin (ET-743, Yondelis) in metastatic uterine leiomyosarcoma. Gynecol Oncol. 2006 Sep;102(3):421-4.

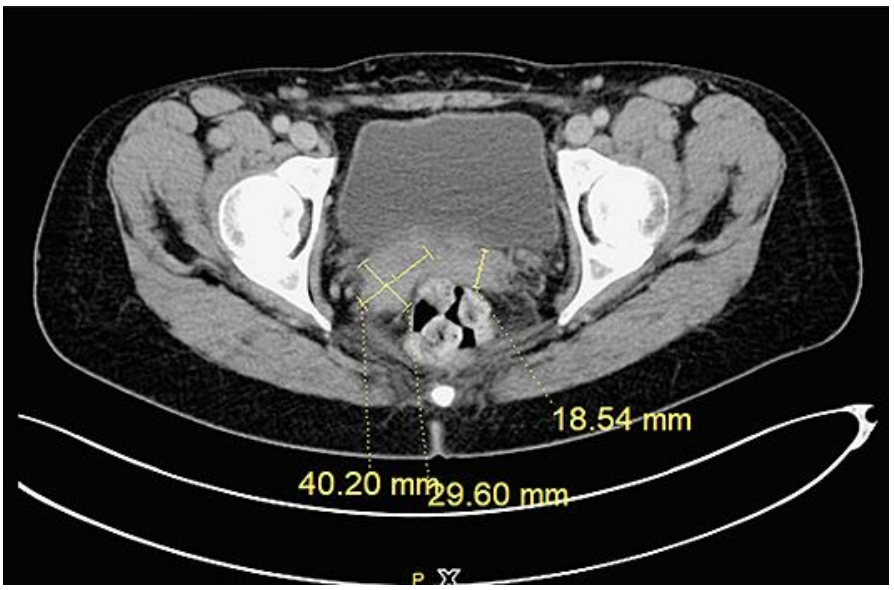

Fig. 1. CT scan showing recurrence of the tumor in the vaginal stump (June 2016).

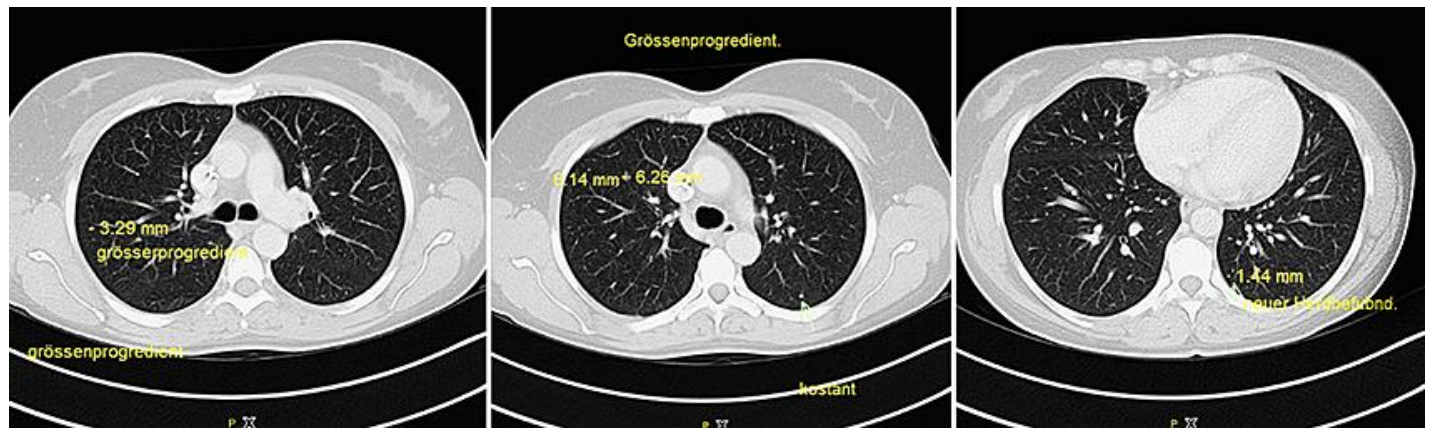

Fig. 2. CT scans showing new lung lesions and progress (October 2016). 


\section{Case Reports in Oncology}

Case Rep Oncol 2018;11:81-89

DOI: $10.1159 / 000486638$

C 2018 The Author(s). Published by S. Karger AG, Basel www.karger.com/cro

Nteli et al.: Long-Lasting Response to Trabectedin in a Patient with Metastatic Uterine Leiomyosarcoma: A Case Report

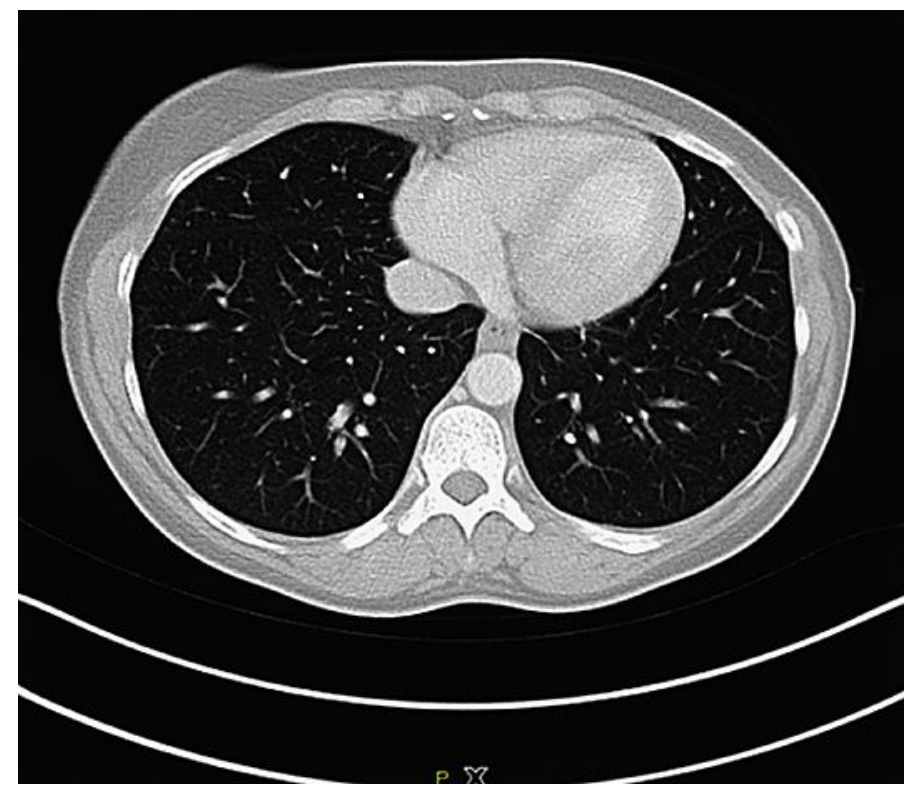

Fig. 3. CT scan showing complete remission of the lung lesions (July 2017).

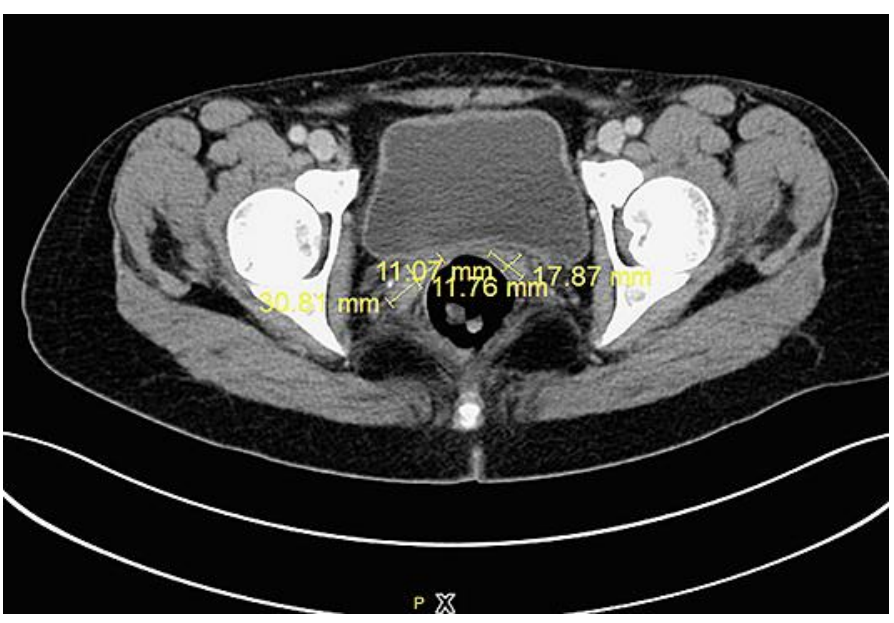

Fig. 4. CT scan showing partial remission of the mass at the vaginal stump after 9 cycles of trabectedin (July 2017). 


\section{Case Reports in Oncology}

Case Rep Oncol 2018;11:81-89

DOI: $10.1159 / 000486638$

(C) 2018 The Author(s). Published by S. Karger AG, Basel www.karger.com/cro

Nteli et al.: Long-Lasting Response to Trabectedin in a Patient with Metastatic Uterine Leiomyosarcoma: A Case Report

Table 1. Case reports in the literature considering the results of trabectedin therapy in metastatic uLMS [26-30]

\begin{tabular}{lllll}
\hline Authors [Ref.], year & Sarcoma type & $\begin{array}{l}\text { Patients, } \\
n\end{array}$ & $\begin{array}{l}\text { Cycles of } \\
\text { trabectedin }\end{array}$ & Response \\
\hline $\begin{array}{l}\text { Tavella et al. [26], } \\
2017\end{array}$ & Metastatic uLMS & 1 & 30 cycles & $\begin{array}{l}\text { Very good partial response, especially at the pulmonary and } \\
\text { pancreatic levels, stable disease at the rest of metastatic sites }\end{array}$ \\
\hline $\begin{array}{l}\text { Bongiovanni et al. [27], } \\
2015\end{array}$ & Metastatic uLMS & 1 & 22 cycles & $\begin{array}{l}\text { Partial response with good tolerability, maintenance of the response } \\
\text { for 10 months after trabectedin withdrawal }\end{array}$ \\
$\begin{array}{l}\text { Corrado et al. [28], } \\
2011\end{array}$ & Metastatic uLMS & 1 & 6 cycles & $\begin{array}{l}\text { Prolonged clinical response in a heavily pretreated patient with lung } \\
\text { metastases of uLMS, improvement of dyspnea symptoms, and } \\
\text { acceptable toxicity profile }\end{array}$ \\
$\begin{array}{l}\text { Amant et al. [29], } \\
2009\end{array}$ & $\begin{array}{l}\text { Three patients with } \\
\text { uLMS, 1 with uterine } \\
\text { adenosarcoma, 1 with } \\
\text { endometrial stromal } \\
\text { sarcoma }\end{array}$ & 5 & $\begin{array}{l}25 \text { cycles were } \\
\text { administered } \\
\text { (mean = 5; } \\
\text { range: 2-12) }\end{array}$ & $\begin{array}{l}\text { Partial response with clinical benefit was noted during 9 months in } \\
1 \text { patient (partial response in an epigastric mass and lung metastasis), } \\
\text { whereas stable disease after 3 months was noted in 1 patient and } \\
\text { progressive disease in 3 patients } \\
\text { Taken together, the response rate was 1 out of 5 for all patients, and } \\
1 \text { out of 3 uLMS responded }\end{array}$ \\
\hline $\begin{array}{l}\text { Tewari et al. [30], } \\
\text { 2006 }\end{array}$ & Metastatic uLMS & 1 & 12 cycles & $\begin{array}{l}\text { A 38-year-old patient with an advanced, recurrent, and refractory } \\
\text { uLMS (lung metastasis, pelvic progression) responded to trabectedin } \\
\text { after failing 4 prior regimens (doxorubicin, gemcitabine, docetaxel, } \\
\text { and ifosfamide) with a durable objective response lasting at least } \\
\text { 8 months }\end{array}$ \\
\hline
\end{tabular}

